\title{
The perceived stress and approach to learning effects on academic performance among Sudanese medical students
}

\author{
Hyder Osman Mirghni ${ }^{1}$, Mohammed Adam Ahmed Elnour ${ }^{2}$
}

${ }^{1}$ MD, Assistant Professor, Medical Department, Faculty of Medicine, University of Tabuk, Saudi Arabia

${ }^{2}$ MD, MHPE, Assistant Professor, Medical Department, Faculty of Medicine, University of Tabuk, Saudi Arabia

\section{Type of article: Original}

\begin{abstract}
Background: There is an increasing awareness of the perceived stress and approach to learning effects on academic achievement.

Objective: This study aimed to assess the educational environment and approach to learning in clinical phase medical students.

Methods: This comparative cross-sectional study was conducted among fifty-nine clinical stage medical students at Omdurman Islamic University (Khartoum, Sudan) during the period from June to August 2016. All the participants signed a written informed consent, then responded to a structured questionnaire to collect demographic data, the two process study questionnaires and the perceived stress questionnaire. The ethical committee of Omdurman Islamic University approved the research, and the Statistical Package for Social Sciences was used to compare the students based on sex, class, and their grades. Data were analyzed by SPSS version 22, using descriptive statistics and t-test.

Results: There were fifty-nine medical students, of whom $41.5 \%$ were males with a mean age of $22.62 \pm 1.84$ years. Stress was evident in the majority of medical students $(88.1 \%)$. The students are using the deep approach to learning more than the superficial approach (The total score was $29.49 \pm 6.39$ for the deep approach, while it was $20.81 \pm 6.94$ for the superficial approach). In the current study, no differences were found regarding sex, class, or grades apart from the superficial approach which was used less among women.

Conclusion: The perceived stress was prevalent among medical students in Omdurman Islamic University, Sudan, the students used the deep approach to learning more than the superficial, no differences were evident in the perceived stress and the learning approach in relation to sex, class level or grades apart from less superficial approach among women.
\end{abstract}

Keywords: Medical students, Academic environment, Approach, Learning, Sudan

\section{Introduction}

Stress is among the most common obstacles to medical education that can negatively impact academic achievement, physical health, and psychological well-being of junior medical students (1). Relatively high levels of depression and anxiety about professional future were previously observed among medical students and junior house staff (2, 3 ). Continuous academic demand, physical fitness, and psychological factors are the most commonly perceived stress causes among this particular group of young adults. Furthermore, researchers have reported that factors like academic constraint, age, sex, and marital status can increase the severity of stress and hence academic performance among medical students $(4,5)$. The aim of medical training is to provide both a physically and mentally active medical professional to build high caliber health care. Obstacles like perceived stress may impede professional development and even a change of career especially during the early stages of training. Early detection of susceptible students, and providing support, could minimize the unwanted consequences of future stress. Continuous stress during medical school could lead to burnout which is a state of mental and physical exhaustion related to work

\section{Corresponding author:}

Assistant Professor Dr. Mohammed Adam Ahmed Elnour, Faculty of Medicine, University of Tabuk, P. O. Box: 741, Tabuk 74171, Kingdom of Saudi Arabia. Tel: +966565880025, Email: mohammedadam1@hotmail.com Received: January 08, 2017, Accepted: February 19, 2017, Published: April 2017 iThenticate screening: February 19, 2017, English editing: March 10, 2017, Quality control: March 12, 2017 (C) 2017 The Authors. This is an open access article under the terms of the Creative Commons Attribution-NonCommercialNoDerivs License, which permits use and distribution in any medium, provided the original work is properly cited, the use is non-commercial and no modifications or adaptations are made. 
or care-giving activities; burnout may result in deleterious consequences on medical students' well-being especially if they continue into residency and beyond (6). The learning process can be affected by two large factors: Student factors such as the approach to learning and learning style, and environmental factors such as teaching pedagogy (7). The learning style can strongly influence academic achievement (8). Thus, it is of prime importance to study the student approach to learning (both process and intention). There are many theories but we consider the in-depth approach which is an effective effort to understand the meaning and to relate it to a conclusion, and the superficial approach in which the effort is to memorize irrelevant facts to fulfill a course requirement (9). To the best of our knowledge, this is the first research to study the perceived stress and the learning process among medical students in Sudan. In this study, we aim to explore the perceived stress and learning approach among medical students in Omdurman Islamic University, and their relation to academic performance

\section{Material and Methods}

This cross-sectional study was conducted among 150 clinical phase medical students at Omdurman Islamic University (Khartoum, Sudan) from June to August 2016. Participants were approached in a ratio of 1:1 to select 75 students. The students were invited to sign a written informed consent, then the Arabic version of the revised study process and the English perceived stress were filled. An orientation meeting was held with the participants to explain the purpose of the survey and how to fill the questionnaire, facilitators were also present during the filling of the questionnaires to solve any difficulties. After drop out of $20 \%$, the sample size stood at fifty-nine students. The perceived stress scale was used and it consisted of a ten-component questionnaire and was well validated (10). Each question was scored as: $0=$ never, $1=$ almost never, $2=$ sometimes, $3=$ fairly often, and $4=$ very often with a sum of forty. A score of fourteen or more is regarded as perceived stress (11). The Arabic version of the Revised Study Process Questionnaire had been previously validated for measuring the study process and consists of twenty items, each with a scale from $1=$ Never or Rarely correct of me to $5=$ Always or almost always true of me (12). IBM $\odot$ SPSS $\odot$ Statistics version 22 (IBMC Corp., Armonk, NY, USA) was used for data analysis, the t-test was used to test the statistical significance, data were presented as percentages and means \pm SD unless otherwise specified. A pvalue of $<0.05$ was considered significant. The ethical committee of Omdurman Islamic University approved the research.

\section{Results}

They were fifty-nine medical students, female dominance was apparent (58.5\%), their ages ranged from 21-25 years old with a mean of $22.62 \pm 1.84$ years; $35.6 \%$ of them scored "A" in the last semester, and $35.6 \%$ were in the 4th class. In the present study, the students were using the deep approach more than the superficial one $(29.49 \pm 6.39$ vs. 20.81 46.94$)$. Table 1 illustrated the learning process among the medical students. Regarding the perceived stress scale components, the students scored worse in the item (Felt confident about your ability to handle your personal problems), followed by (Been able to control irritations in your life) with a maximum overall score of 22.81 \pm 6.94 . The different components of the perceived stress scale were shown in Table 2. In the current study, no significant

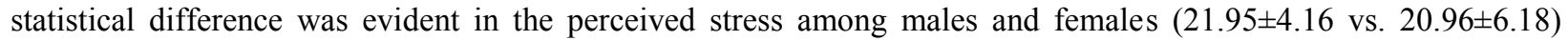
$(\mathrm{p}=0.519)$, fourth and fifth class $(21.57 \pm 5.12$ vs. $20.77 \pm 5.85)(\mathrm{p}=0.611)$, and the scores in the last semester $(21.00 \pm 3.89$ vs. $20.40 \pm 4.46)(\mathrm{p}=0.830)$. In the current study, the females adopted the deep approach more than males with no significant statistical difference $(30.36 \pm 7.54$ vs. $28.59 \pm 5.22)(\mathrm{p}=0.362)$; the women also took the superficial approach less than men with a significant statistical difference $(20.40 \pm 7.08$ vs. $26.05 \pm 5.98)(p=0.003)$. The fifth-class medical students were using the deep approach more than the fourth medical students $(30.34 \pm 6.76 \mathrm{vs}$. $27.83 \pm 5.37)(\mathrm{p}=0.178)$, and $(21.74 \pm 6.62$ vs. $24.89 \pm 7.27)(\mathrm{p}=0.119)$. The deep approach was used more among

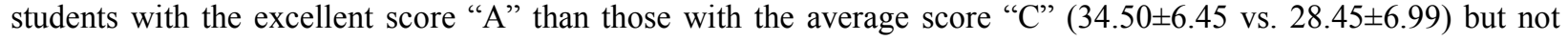
reaching statistical significance $(\mathrm{p}=0.122)$ (Table 3$)$. It is interesting to note that the perceived stress was evident in the majority $(88.1 \%)$ of medical students, more than two-thirds of medical students were using the deep approach to learning (71.5\%), and $22.6 \%$ were adopting the superficial approach, while $1.9 \%$ were using both methods equally.

Table 1. The components of the study process among the study group

\begin{tabular}{|l|c|}
\hline Character & Mean \pm SD \\
\hline Deep motive & $14.79 \pm 3.91$ \\
\hline Deep strategy & $14.70 \pm 3.20$ \\
\hline Deep approach (Deep motive + deep strategy) & $29.49 \pm 6.39$ \\
\hline Superficial motive & $10.42 \pm 3.62$ \\
\hline Superficial strategy & $10.40 \pm 3.89$ \\
\hline Superficial approach (Superficial motive + superficial strategy) & $20.82 \pm 6.94$ \\
\hline
\end{tabular}


Table 2. The different components of the perceived stress scale among medical students

\begin{tabular}{|l|l|l|}
\hline Character & Mean & SD \\
\hline Been upset because of something that happened unexpectedly & 2.40 & 1.16 \\
\hline Felt that you were unable to control the important things in your life & 2.11 & 1.23 \\
\hline Felt nervous and stressed & 2.64 & 1.11 \\
\hline Felt confident about your ability to handle your personal problems & 1.62 & 1.12 \\
\hline Felt that things were going your way & 1.93 & 1.08 \\
\hline Found that you could not cope with all the things that you had to do & 2.11 & 0.93 \\
\hline Been able to control irritations in your life & 1.79 & 1.15 \\
\hline Felt that you were on top of things & 2.18 & 1.12 \\
\hline Been angered because of things that were outside of your control & 2.08 & 1.32 \\
\hline Felt difficulties were piling up so high that you could not overcome them & 2.20 & 1.15 \\
\hline Overall perceived stress score & 22.81 & 6.94 \\
\hline
\end{tabular}

Table 3. The relation between different approach to learning and sex, class, and grades of students

\begin{tabular}{|l|l|l|l|l|l|}
\hline Character & Deep approach $($ Mean \pm SD) & $p$-value & Superficial approach $($ Mean \pm SD) & $p$-value \\
\hline \multirow{2}{*}{ Sex } & Male & $28.59 \pm 5.22$ & 0.362 & $26.05 \pm 5.98$ & 0.003 \\
\cline { 2 - 3 } & Female & $30.36 \pm 7.54$ & & $20.40 \pm 7.08$ & \\
\hline \multirow{2}{*}{ Class } & Forth & $27.83 \pm 5.37$ & 0.178 & $24.89 \pm 7.27$ & \multirow{2}{*}{0.119} \\
\cline { 2 - 3 } & Fifth & $30.34 \pm 6.76$ & & $21.74 \pm 6.62$ & \\
\hline \multirow{2}{*}{ Grades } & Excellent (A) & $34.50 \pm 6.45$ & 0.122 & $23.75 \pm 10.56$ & \\
\cline { 2 - 5 } & Pass (C) & $28.45 \pm 6.99$ & 0.122 & $23.82 \pm 7.68$ & \\
\hline
\end{tabular}

\section{Discussion}

The present study was performed to assess the perceived stress and the learning approach among Sudanese clinical phase medical students in which $88.1 \%$ of medical students' perceived stress similar to a study from Iran 12 in which $83 \%$ of medical students reported stress. Researchers from Malaysia conducted a study among undergraduate medical students and concluded similar results (13). In the current study, the female medical students perceived stress more than males but not reaching statistical significance, in contradiction to the previous 12 study in which the perceived stress was 3.12 times higher among females. The poor learning environment, recreational facilities, and the lesser educational facilities observed in the previous study may not apply to our study. In line with the previous study is the lack of difference in the perceived stress between the fourth and fifth class medical students in the current study. The present data showed no significant statistical difference in academic achievement between students with and without perceived stress in accordance with Shah et al. (14) who conducted a study in Pakistan and concluded similar findings. A study carried out among medical students (15) before the progress found that the superficial approach to learning, but not the perceived stress, was negatively associated with students' scores in line with the current observation. In the present study, the deep approach was more common among the study group in similarity to a survey carried out in Nepal (16), and concluded that the deep approach was used among medical students regardless of age or sex. The current data showed that women adopted the superficial approach less than men and the deep approach more in agreement with Cumplido-Hernández et al. (17) who observed a higher deep approach among females. The current study showed no differences in grades between the students who adopted the deep approach more than the superficial approach, in line with Naqvi et al. (18) who showed no correlation between approach to learning and success in the examinations. Our study was in contradiction to Wards (19) who observed better academic achievement among the deep approach, medical students. Previous literature (16) concluded a higher deep approach to learning among the first class medical students with a tendency for a lower deep approach in the second year attributed to the reduction of intrinsic motivation and strategies adopted for deep learning. In the present study, no differences were evident between the 4th and 5th class medical students regarding their approach to learning; one plausible examination is the similarity of the curriculum and the mode of assessment in these courses.

\section{Conclusions}

The perceived stress was prevalent among Sudanese medical students, and the students used the deep approach more, with the women adopting the superficial approach less than men. There were no differences between students in the perceived stress and the learning approach regarding sex, class, or academic achievement, apart from the superficial approach which was less among females. The result of this research should be viewed in the presence of 
the following limitations: The small size of the present sample, the study was conducted at a single school of medicine so generalization can not be ensured, and the reliance on a self-administered questionnaire which is more prone to subjectivity.

\section{Acknowledgments:}

The authors thanks the Omdurman Islamic University (Khartoum, Sudan) for help in this study.

\section{Conflict of Interest:}

There is no conflict of interest to be declared.

\section{Authors' contributions:}

All authors contributed to this project and article equally. All authors read and approved the final manuscript.

\section{References:}

1) Mosley TH Jr, Perrin SG, Neral SM, Dubbert PM, Grothues CA, Pinto BM. Stress, Coping, and well-being among third-year medical students. Acad Med. 1994; 69: 765-7. doi: 10.1097/00001888-199409000-00024. PMID: 8074778.

2) Baldassin S, Alves TC, de Andrade AG, Nogueira Martins LA. The characteristic of depressive symptoms in medical students during medical education and training: A cross sectional study. BMC Med Educ. 2008; 8: 60. doi: 10.1186/1472-6920-8-60. PMID: 19077227, PMCID: PMC2621219.

3) Bolanowski W. Anxiety about professional future among young doctors. Int J Occup Med Environ Health. 2005; 18(4): 367-74. PMID: 16617853.

4) Supe AN. A Study of stress in medical students at GS Seth Medical College. J Postgrad Med. 1998; 44(1): 1-6. PMID: 10703558.

5) Hatcher L, Prus JS, Englehard B, Farmer TM. A measure of academic educational constraints: Out-ofClass circumstances that inhibit college students development. Educ Psychol Meas. 1991; 51(4): 953-62. doi: $10.1177 / 001316449105100415$.

6) Ishak W, Nikravesh R, Lederer S, Perry R, Ogunyemi D, Bernstein C. Burnout in medical students: a systematic review. Clin Teach. 2013; 10(4): 242-5. doi: 10.1111/tct.12014. PMID: 23834570.

7) Newble DI, Entwistle NJ. Entwistle. Learning styles and approaches: implication for medical education. Med Educ. 1986; 20(3): 162-75. doi: 10.1111/j.1365-2923.1986.tb01163.x. PMID: 3724571.

8) Burton L, Nelson L. The relationships between personality, approaches to learning and academic success in first-year psychology distance education students. Critical visions: thinking, learning and researching in higher education Proceedings of the 29th HERDSA Annual Conference. Perth: Western Australia. 2006; 64-72.

9) Al-qahtani MF. Associations between approaches to study, the learning environment, and academic achievement. Journal of Taibah University Medical Sciences. 2015; 10(1): 56-65. doi: 10.1016/j.jtumed.2015.01.014.

10) Munshi FM, Al-Rukban MO, Al-Hoqail I. Reliability and validity of an Arabic version of the revised twofactor study process questionnaire R-SPQ-2F. J Family Community Med. 2012; 19(1): 33-7. doi: 10.4103/2230-8229.94010. PMID: 22518356, PMCID: PMC3326768.

11) Cohen S, Kamarck T, Mermelstein R. A global measure of perceived stress. J Health Soc Behav. 1983; 24(4): 385-96. doi: 10.2307/2136404. PMID: 6668417.

12) Borjalilu S, Mohammadi A, Mojtahedzadeh R. Sources and Severity of Perceived Stress Among Iranian Medical Students. Iran Red Crescent Med J. 2015; 17(10): e17767. doi: 10.5812/ircmj.17767. PMID: 26568843, PMCID: PMC4636747.

13) Sherina MS, Rampal L, Kaneson N. Psychological stress among undergraduate medical students. Med J Malaysia. 2004; 59(2): 207-11. PMID: 15559171.

14) Shah M, Hasan S, Malik S, Sreeramareddy CT. Perceived stress, sources and severity of stress among medical undergraduates in a Pakistani medical school. BMC Med Educ. 2010; 10: 2. doi: 10.1186/14726920-10-2.

15) Chen Y, Henning M, Yielder J, Jones R, Wearn A, Weller J. Progress testing in the medical curriculum: students' approaches to learning and perceived stress. BMC Med Educ. 2015; 15: 147. doi: 10.1186/s12909-015-0426-y. 
16) Shah DK, Yadav RL, Sharma D, Yadav PK, Sapkota NK, Jha RK, et al. Learning approach among health sciences students in a medical college in Nepal: a cross-sectional study. Adv Med Educ Pract. 2016; 7: 13743. doi: 10.2147/AMEP.S100968. PMID: 27019603, PMCID: PMC4786058.

17) Cumplido-Hernández G, Campos-Arciniega MF, Chávez-López A, Pérez-García V. [Learning approaches used by undergraduate interns in the development of a medical specialty]. Rev Med Inst Mex Seguro Soc. 2006; 44(4): 321-8. PMID: 16904035.

18) Naqvi $Z$, Ahmed R. Learning approaches and academic performance of undergraduate medical students in Pakistan. J Pak Med Assoc. 2000; 50(1): 20-5. PMID: 10770043.

19) Ward PJ. Influence of study approaches on academic outcomes during pre-clinical medical education. Med Teach. 2011; 33(12): e651-62. doi: 10.3109/0142159X.2011.610843. PMID: 22225447. 